\title{
Elaboração de embutido fermentado tipo salame utilizando carne de ovelhas de descarte
}

\author{
Elaboration of fermented sausage type salami using meat from culling ewe
}

\author{
Luis Fernando Vilani De PELEGRINI ${ }^{1 *}$, Cleber Cassol PIRES ${ }^{2}$, Nelcindo Nascimento TERRA ${ }^{3}$, \\ Paulo Cezar Bastianello CAMPAGNOL ${ }^{3}$, Diego Barcelos GALVANI ${ }^{4}$, Ricardo Monteiro CHEQUIM ${ }^{4}$
}

\begin{abstract}
Resumo
O objetivo deste trabalho foi produzir embutido fermentado com carne de ovelhas de descarte de dois grupos genéticos em dois sistemas de alimentação. Foram utilizadas 10 ovelhas da raça Ideal e 10 da raça Texel, as quais foram aleatoriamente distribuídas de acordo com o grupo racial, em dois sistemas alimentares: confinamento e pastagem cultivada. Os animais foram abatidos quando atingiram um escore corporal médio de 3,5 pontos. Na produção dos embutidos utilizou-se $80 \%$ de carne ovina e $20 \%$ de carne suína. Foram realizadas as determinações de $\mathrm{pH}$, atividade de água, quebra de peso e análise sensorial, utilizando uma escala hedônica de 7 pontos, avaliando os atributos de cor, odor, textura e sabor. Não foram encontradas diferenças entre grupos genéticos $(\mathrm{p}>0,05)$ e sistema alimentar $(\mathrm{p}>0,05)$. Os valores médios no painel sensorial, considerando os grupos genéticos, variaram de 4,90 a 5,41 para a coloração; 4,53 a 4,81 para o odor; 5,25 a 5,75 para o sabor e 5,40 a 5,69 para a textura, já para os métodos de alimentação variaram de 5,03 a 5,25; 4,56 a 4,78; 5,50 e 5,34 a 5,75 para a coloração, odor, sabor e textura, respectivamente. Pode-se concluir que os embutidos fermentados foram aprovados sensorialmente pelos provadores.
\end{abstract}

Palavras-chave: ovelha; salame; análise sensorial.

\begin{abstract}
The aim of this work was producing fermented sausage with meat of culling ewe of two genetic groups in two feeding systems. 10 ewes of the Ideal breed and 10 of the Texel breed were used in the experiment, which were randomly distributed in agreement with the breed group in two alimentary systems: confinement and cultivated pasture. The animals were slaughtered when they reached a medium corporal score of 3.5 points. For the production of the sausages, a proportion of $80 \%$ of ewe meat and $20 \%$ of pork meat were used. The $\mathrm{pH}$, water activity, weight loss, and sensorial analysis, were determinated using a scale of 7 points evaluating the color, odor, texture, and flavor attributes of the fermented sausages. No differences were not found among the genetic groups ( $p>0,05)$ and the alimentary system ( $p>0,05)$. The average values in the sensorial panel varied from 4,90 to 5,41 for coloration; 4,53 to 4,81 for odor; 5,25 to 5,75 for flavor and from 5,40 to 5,69 for texture. For the feeding methods they varied from 5,03 to 5,25; 4,56 to 4,78; 5,50, and 5,34 to 5,75 for coloration, odor, flavor, and texture, respectively, considering the genetic groups. It can be concluded that the sausages fermented were sensory approved by the tasters.

Keywords: ewe; salami; sensorial analysis.
\end{abstract}

\section{Introdução}

A carne ovina é uma fonte de proteína semelhante às outras espécies. No entanto, o seu consumo sofre restrições devido a fatores que envolvem desde a cadeia produtiva, preço, disponibilidade de oferta e também aos aspectos qualitativos da mesma.

Sobre estes se destaca a carne de ovelhas velhas ou de descarte, sem condições ideais para o consumo in natura, devido principalmente à despadronização das carcaças e a condições higiênico-sanitárias inadequadas dos abates, o que vem a prejudicar a comercialização. A utilização desta carne na forma de embutidos fermentados tipo salame poderia ser uma alternativa para um melhor aproveitamento da mesma, pois além de auxiliar na melhoria do sabor, este produto é estável à temperatura ambiente e agrega valor a esta matéria-prima, que é de difícil comercialização junto à cadeia da carne, principalmente quando se compara com a carne de cordeiros.

Com relação ao aproveitamento da carne proveniente de animais mais velhos, Silveira e Andrade (1991) recomendam sua utilização na formulação de produtos fermentados porque estes apresentam um teor de umidade mais baixo e uma coloração mais acentuada. Segundo Zapata (1994), Melo (1998) e Batista (1999), animais de descarte podem ser aproveitados em embutidos cozidos, defumados e/ou fermentados, como por exemplo, salames (carnes bovina, suína e ovina/ caprina, contendo toucinho), "krakauer" (embutido de carne ovina/ caprina e suína), "iyoner" (produto de composição similar aos

\footnotetext{
Recebido para publicação em 18/6/2007

Aceito para publicação em 4/3/2008 (002529)

Departamento de Medicina Veterinária Preventiva, Centro de Ciências Rurais, Universidade Federal de Santa Maria - UFSM, Faixa de Camobi, Km 9, camobi,

CEP 97105900, Santa Maria, RS, Brasil, E-mail: pelegrini@smail.ufsm.br

2 Departamento de Zootecnia, Universidade Federal de Santa Maria - UFSM, Centro Nacional de Desenvolvimento Científico e Tecnológico - CNPq

3 Departamento de Tecnologia e Ciência dos Alimentos, Universidade Federal de Santa Maria - UFSM, Centro Nacional de Desenvolvimento Científico e Tecnológico - CNPq

${ }^{4}$ Departamento de Zootecnia, Universidade Federal de Santa Maria - UFSM

${ }^{*}$ A quem a correspondência deve ser enviada
} 
salames, porém sem sofrer fermentação), salsichas tipo Viena, embutidos tipo apresuntado e hambúrguer.

Roça et al. (1997) estudaram a viabilidade de elaboração de alguns produtos de carne de ovelha, como presunto, fiambre, charque, jerked beef e salame, em escala de laboratório, comparando-os com produtos de carne de cordeiro. Esses autores utilizaram a carne de uma ovelha com seis anos e de um cordeiro de oito meses de idade, sendo que o salame obtido com carne de ovelha apresentou cor mais característica do produto, sem afetar os outros parâmetros sensoriais, e concluíram que a elaboração de salame é uma alternativa para o aproveitamento da carne de ovinos de descarte.

Este trabalho teve por objetivo produzir e avaliar sensorialmente embutidos fermentados tipo salame utilizando carne de ovelhas de descarte de dois grupos genéticos submetidas a dois sistemas de alimentação.

\section{Material e métodos}

O experimento foi conduzido no Setor de Ovinocultura do Departamento de Zootecnia e no Departamento de Tecnologia e Ciência dos Alimentos da Universidade Federal de Santa Maria - RS, no período compreendido entre os meses de julho e dezembro de 2005.

Foram utilizadas 20 ovelhas, de mesma idade (boca cheia com desgaste visível das pinças) e condição corporal (2,5; onde: 1 - muito magro e 5 - muito gordo) (RUSSEL; DONEY; GUNN, 1969), sendo: 10 da raça Ideal e 10 da raça Texel, as quais foram aleatoriamente distribuídas, de acordo com o grupo genético, nos sistemas alimentares: confinamento e pastagem cultivada, constituindo os tratamentos: ovelhas da raça Ideal terminadas em confinamento (IC); ovelhas da raça Ideal terminadas em pastagem cultivada (IP); ovelhas da raça Texel Terminadas em Confinamento (TC) e ovelhas da raça Texel terminadas em pastagem cultivada (TP).

A pastagem foi implantada pelo sistema de preparo mínimo, utilizando-se uma mistura de aveia preta (Avena strigosa Schreb.) e azevém (Lolium multiflorum Lam.), cuja densidade de sementes foi de 70 e $25 \mathrm{~kg} . \mathrm{ha}^{-1}$, respectivamente. A adubação de base constou de $150 \mathrm{~kg} \cdot \mathrm{ha}^{-1}$ de adubo NPK na fórmula 5-20-20, sendo distribuídos ainda kg.ha ${ }^{-1}$ de $\mathrm{N}$, na forma de uréia, em 3 aplicações. A área total da pastagem foi subdividida em dois piquetes com área média de 0,40 ha, sendo alocadas, em cada um destes, cinco ovelhas-teste e um número variável de reguladoras. A massa e a oferta de forragem pretendidas durante o período experimental foram, respectivamente, $1200 \mathrm{~kg} \cdot \mathrm{ha}^{-1} \mathrm{MS}$ e $10 \%$.

A dieta fornecida aos animais confinados, calculada de acordo com os requerimentos especificados pelo $\mathrm{NRC}^{9}$, foi composta por 59,5\% de silagem de sorgo (Sorghum bicolor (L.) Moench), $25,5 \%$ de grão de milho (Zea mays L.) triturado, $13,8 \%$ de farelo de soja (Glycine max L.), 0,6\% de sal comum, 0,54\% de calcário calcítico e $0,10 \%$ de fosfato bicálcico, de forma a totalizar $13 \%$ de PB e 75\% de NDT (MS). Os animais foram alimentados ad libitum duas vezes ao dia, às 8:00 e 17:00 horas.

$\mathrm{O}$ abate foi realizado assim que as ovelhas de cada grupo genético alcançaram o escore médio de condição corporal de
3,5, observando-se um jejum prévio de 14 horas. Após o abate, as carcaças permaneceram durante 24 horas em câmara fria com temperatura de $4{ }^{\circ} \mathrm{C}$. Posteriormente foi realizada a classificação das carcaças e a retirada dos cortes comerciais. Para a produção dos embutidos foram utilizados $80 \%$ de carne ovina e $20 \%$ de carne suína (pernil), adquiridas no comércio local. A carne ovina utilizada foi retirada da paleta e do pescoço de cada carcaça e misturada proporcionalmente, de modo a constituir uma quantidade única e representativa dos cortes de aproximadamente $10 \mathrm{~kg}$, sendo posteriormente congelada.

Após descongelamento de 24 horas em refrigerador doméstico, as carnes ovina e suína sofreram um processo de toalete, quando se retirou a gordura superficial, ossos, nervos e tendões. Em seguida, as carnes ovina e suína foram moídas em disco de $8 \mathrm{~mm}$ e colocadas em misturadeira, adicionandose cloreto de sódio (2,5\%) e misturando-se durante 3 minutos para a extração das proteínas miofibrilares. A seguir, foram acrescentados os demais ingredientes: glicose $(0,5 \%)$, mistura de sais de cura $(0,3 \%)$, eritorbato de sódio $(0,25 \%)$, pimenta branca $(0,2 \%)$, alho $(0,3 \%)$ e noz moscada $(0,02 \%)$. Após a total homogeneização da massa cárnea, os ingredientes foram incorporados à cultura starter Germinal $(0,02 \%)$, contendo os microrganismos Pediococcus pentosaceus e Staphylococcus carnosus. A cultura starter foi previamente diluída em água destilada, isenta de cloro, 30 minutos antes da adição à mistura. A massa foi embutida em tripa bovina natural, previamente imersa em uma solução gelada de ácido láctico a 1\%, e cortada em peças de aproximadamente $15 \mathrm{~cm}$ de comprimento. Após o embutimento, as amostras foram encaminhadas para a câmara climatizada, com temperatura e umidade relativa controlada, onde permaneceram durante 28 dias. A programação de temperatura e umidade relativa (UR) foram as seguintes: primeiro dia, temperatura de $25{ }^{\circ} \mathrm{C} /$ U.R. $95 \%$; segundo dia, $24{ }^{\circ} \mathrm{C} / 93 \%$; terceiro dia, $23{ }^{\circ} \mathrm{C} / 90 \%$; quarto dia, $22{ }^{\circ} \mathrm{C} / 85 \%$; quinto dia, $21{ }^{\circ} \mathrm{C} / 80 \%$; sexto dia, $20{ }^{\circ} \mathrm{C} / 75 \%$; e sétimo dia em diante, $18^{\circ} \mathrm{C} / 75 \%$. Concluída a fabricação, retiraram-se as tripas, e as peças dos embutidos fermentados foram embaladas a vácuo e armazenadas à temperatura ambiente.

Durante o processamento foram realizadas análises em triplicata, determinando-se o $\mathrm{pH}$, segundo técnica descrita por Terra e Brum (1988); nos dias zero, 1, 2, 3, 4, 5, 6, 7, 14, 21 e 28, atividade de água (Aw), utilizando aparelho Testo $400 \mathrm{CE}$ (Testo GMBH \& CO.) nos dias zero, 14, 21 e 28, e perda de peso através da diferença de peso existente entre as peças cárneas no momento do embutimento e após o produto acabado (TERRA; BRUM, 1988).

Foi realizado no produto pronto, um teste sensorial de aceitação, avaliando-se os atributos de cor, aroma, sabor e textura, utilizando uma escala hedônica estruturada de sete pontos, variando de desgostei muitíssimo (nota 1) a gostei muitíssimo (nota 7). O teste de aceitação foi realizado em cabines individuais no Laboratório de Análise Sensorial do Departamento de Tecnologia e Ciência dos Alimentos da UFSM, no turno da manhã, das 9:30 às 11:30. Para avaliação das amostras foram utilizados 30 provadores não treinados, mas consumidores de salame. As amostras foram oferecidas aos painelistas em pratos 
plásticos brancos, codificados com três dígitos, acompanhadas de um copo de água e biscoito do tipo água e sal.

Foi utilizado um delineamento inteiramente casualizado num arranjo fatorial $2 \times 2$, onde cada peça constituiu uma parcela e cada alíquota a subparcela. Os dados foram submetidos à análise de variância cujo modelo incluiu os efeitos de genótipo, sistema alimentar, interação genótipo X sistema alimentar e erro experimental, e ao teste $F$ a 5\% de probabilidade. As análises foram realizadas com auxílio do pacote estatístico SAS (1997).

\section{Resultados e discussão}

A Figura 1 mostra a evolução do $\mathrm{pH}$ durante o processamento dos embutidos fermentados de carne ovina. Os dados encontrados mostram que após 48 horas de maturação ocorreu uma queda do $\mathrm{pH}$ para valores inferiores dos recomendados por Coventry e Hickey (1991), que afirmam que para o microrganismo Staphylococcus aureus ser inibido por bactérias ácido lácticas, deve ocorrer uma queda de $\mathrm{pH}$ até o valor de 5,2 dentro de 48 horas.

Segundo Buckenhüskes (1993), a queda do $\mathrm{pH}$ deve ocorrer até o sétimo dia, de forma gradual para valores em torno

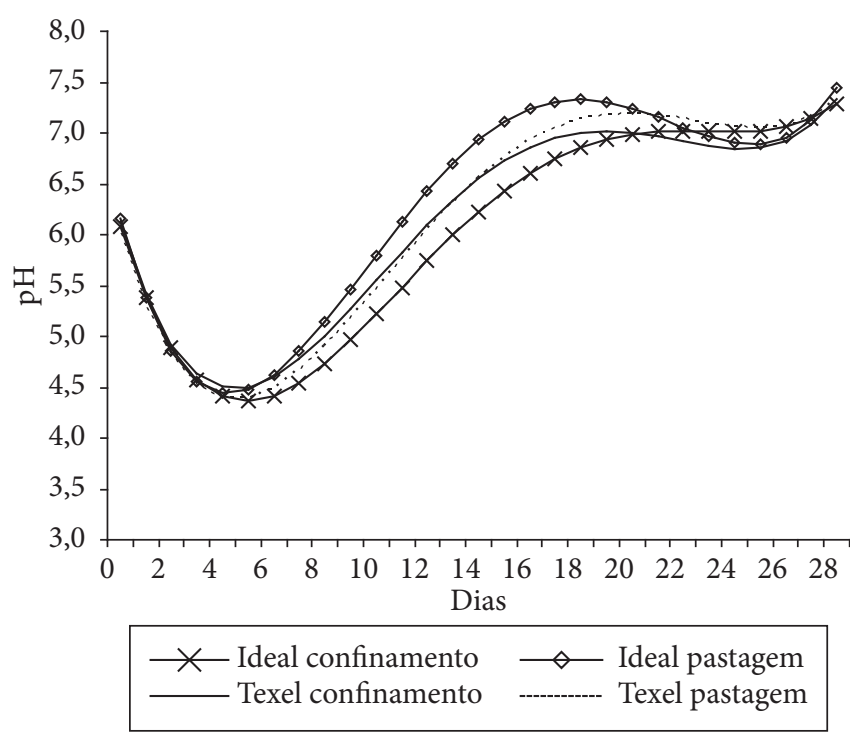

Ideal em Confinamento (IC)

$\mathrm{pH}=6,077-0,8044^{\star} \mathrm{dia}+0,1168^{\star} \mathrm{dia}^{2}-0,0053^{\star} \mathrm{dia}^{3}+$ $0,00008^{\star} \operatorname{dia}^{4}\left(R^{2}=0,9561\right)$

Ideal em Pastagem (IP)

$\mathrm{pH}=6,161-0,9356^{\star} \mathrm{dia}+0,1553^{\star} \mathrm{dia}^{2}-0,0078^{\star} \mathrm{dia}^{3}+$ $0,00012^{\star} \operatorname{dia}^{4}\left(R^{2}=0,9538\right)$

Texel em Confinamento (TC)

$\mathrm{pH}=6,120-0,8366^{\star} \mathrm{dia}+0,1320^{\star} \mathrm{dia}^{2}-0,0064^{\star} \mathrm{dia}^{3}+$ $0,00010^{*} \operatorname{dia}^{4}\left(\mathrm{R}^{2}=0,9468\right)$

Texel em Pastagem (TP)

$\mathrm{pH}=6,011-0,8290^{\star} \mathrm{dia}+0,1290^{\star} \mathrm{dia}^{2}-0,0061^{\star} \mathrm{dia}^{3}+$ $0,00009^{*} \operatorname{dia}^{4}\left(R^{2}=0,9742\right)$

Figura 1. Evolução do $\mathrm{pH}$ dos embutidos fermentados de carne ovina. de cinco, devido à liberação de ácido láctico, formado a partir da fermentação de hexoses pelas bactérias ácido lácticas. A partir do sétimo dia, os valores de $\mathrm{pH}$ sofrem um aumento, pois ocorrem reações de descarboxilação e desaminação de aminoácidos, que liberam amônia no meio, alcalinizando-o (ORDÓÑEZ et al., 1999).

Neste experimento foi observada uma queda inicial do $\mathrm{pH}$ em todos os tratamentos, em decorrência do processo fermentativo, seguida de um rápido aumento dos valores de $\mathrm{pH}$. Isto ocorreu provavelmente devido à degradação do ácido láctico e liberação de amoníaco, causada pela microbiota fúngica superficial (CASTRO; LUCHESE; MARTINS, 2000). De forma similar, Rodel, Stiebing e Krockel (1993), utilizando temperaturas de fermentação semelhantes às utilizadas neste experimento, observaram metabolismo fúngico demasiadamente acentuado, resultando em $\mathrm{pH}$ final muito elevado. Estes autores empregaram dois métodos de processamento, sendo que no primeiro usaram temperaturas de 24 a $18{ }^{\circ} \mathrm{C}$ por 7 dias, e no segundo 25 a $19^{\circ} \mathrm{C}$ durante 36 horas, em seguida houve uma redução de 8 a $10^{\circ} \mathrm{C}$ até o final do período de maturação. Com o primeiro método, os salames apresentaram um leve, mas completo, recobrimento com mofos a partir do terceiro dia, apresentando-se totalmente recobertos no oitavo dia, semelhante ao ocorrido no presente trabalho. Já no segundo método, observaram a cobertura total dos salames com mofos somente após três semanas. Entretanto, este retardo no desenvolvimento dos mofos influenciou favoravelmente a evolução do $\mathrm{pH}$ do produto. No primeiro método houve um abaixamento inicial do $\mathrm{pH}$ do embutido, seguido de um rápido aumento devido ao crescimento dos mofos.

Logo após o embutimento, obtiveram-se valores de atividade de água $(\mathrm{Aw})$ iguais a 0,96 para todos os tratamentos. Foi verificada uma diminuição dos valores durante o processamento, sendo que após 28 dias de maturação a Aw foi inferior a 0,87 em todos os lotes, o que é desejável para a estabilidade do produto à temperatura ambiente, pois de acordo com Leistner e Roedel (1975), produtos cárneos que apresentam $\mathrm{pH}<5,0$ ou Aw $<0,91$, ou ainda, $\mathrm{pH} \leq 5,2$ e Aw $\leq 0,95$ são considerados estáveis e podem ser conservados sem refrigeração.

Os valores médios da percentagem de perda de peso e do teste de aceitação sensorial são apresentados na Tabela 1. A perda de peso dos embutidos fermentados tipo salame foi influenciada pelo grupo genético, sendo que os salames elaborados com carne de ovinos da raça Texel apresentaram uma maior percentagem de perda de peso que os provenientes da raça Ideal. Durante o processo de dessecação, a perda de peso considerada ideal para produtos fermentados secos está entre 30 e $40 \%$. Perdas de peso maiores que esses valores dificultam a viabilidade econômica dos produtos (RUST, 1994). A perda excessiva de peso (51,86 a $54,81 \%$ ) ocorreu provavelmente devido a não utilização de toucinho na formulação, fato este determinado pela necessidade de não interferir no ensaio sensorial. Concordando com estes resultados, Campagnol et al. (2007) ao avaliarem salames produzidos sem toucinho na formulação observaram uma perda de peso similar à encontrada neste trabalho.

Pode-se observar que os atributos de cor, odor, sabor e textura não foram influenciados pelo sistema alimentar e pelo grupo genético (Tabela 1). Os valores obtidos para todas as 
Tabela 1. Valores médios da perda de peso e dos testes de aceitação para cor, aroma, sabor e textura dos embutidos fermentados de carne ovina.

\begin{tabular}{lccccc}
\hline & $\begin{array}{c}\text { Perda de } \\
\text { peso (\%) }\end{array}$ & Cor & Odor & Sabor & Textura \\
\hline Raça & & & & & \\
Ideal & 51,86 & 5,41 & 4,81 & 5,75 & 5,69 \\
Texel & 54,81 & 4,90 & 4,53 & 5,25 & 5,40 \\
F & 11,21 & 2,84 & 0,63 & 3,87 & 1,27 \\
P & 0,0101 & 0,0969 & 0,4320 & 0,0538 & 0,2648 \\
Sistema alimentar & & & & & \\
Confinamento & 52,83 & 5,25 & 4,78 & 5,50 & 5,34 \\
Pastagem & 53,11 & 5,03 & 4,56 & 5,50 & 5,75 \\
F & 0,17 & 0,71 & 0,38 & 0,00 & 2,64 \\
P & 0,6910 & 0,4024 & 0,5406 & 1,00 & 0,1092 \\
Raça X sistema alimentar & & & & & \\
F & 5,14 & 2,18 & 0,38 & 0,00 & 0,02 \\
P & 0,0531 & 0,1452 & 0,5406 & 1,00 & 0,9009 \\
Média & 52,97 & 5,15 & 4,67 & 5,50 & 5,55 \\
CV (\%) & 2,17 & 22,99 & 30,43 & 18,48 & 18,02 \\
\hline
\end{tabular}

variáveis analisadas corresponderam a "não gostei nem desgostei" (nota 4) a "gostei moderadamente" (nota 5), o que mostra que os embutidos fermentados produzidos com $80 \%$ de carne ovina e $20 \%$ de carne suína foram aprovados pelos painelistas. Este resultado é coerente com o estudo de Klettner et al. (1989), que consideraram satisfatórios, sensorialmente, os embutidos fermentados produzidos com carne de ovinos de descarte na proporção de $33 \%$, junto de carne suína e bovina.

\section{Conclusões}

Os embutidos fermentados com $80 \%$ de carne de ovelhas de descarte mais $20 \%$ de carne suína são aceitos por consumidores de salame, sendo sua elaboração uma alternativa importante para agregar valor à carne de ovelhas de descarte. No entanto, novos trabalhos devem ser realizados utilizando-se carne suína em diferentes proporções, com a finalidade de atingir um melhor nível de aceitabilidade.

\section{Referências bibliográficas}

BATISTA, A. S. M. Estudo da elaboração e estabilidade de um embutido cru reestruturado tipo hambúrguer a base de caprinos de descarte. Ceará, 1999. 68 f. Dissertação - (Mestrado em Tecnologia de Alimentos), Universidade Federal do Ceará.
BUCKENHÜSKES, H. J. Selection criteria for lactic acid bacteria to be used as cultures for various food commodities. FEMS Microbiology Reviews, v. 12, n. 1-3, p. 253-272, 1993.

CAMPAGNOL, P. C. B. et al. Salame elaborado com Lactobacillus plantarum fermentado em meio de cultura de plasma suíno. Ciência e Tecnologia de Alimentos, v. 27, n. 4, p. 883-889, 2007.

CASTRO, L. C.; LUCHESE, R. H.; MARTINS, J. F. P. Efeito do uso da cepa starter de Penicillium nalgiovense na qualidade de salames. Ciência e Tecnologia de Alimentos, v. 20, n. 1, p. 40-46, 2000.

COVENTRY, J.; HICKEY, M. W. Growth characteristics of meat starter cultures. Meat Science, v. 30, n. 1, p. 41-48, 1991.

KLETTNER, P. G.; POLLEIN, H.; OTT, G. Processing of old sheep in the meat industry. Fleischwirtschaft, v. 69 , n. 12, p. 1810-1835, 1989.

LEISTNER, L.; ROEDEL, W. The significance of water activity for microrganisms in meats. In: DUCKWORTH, R. B. Water relations of foods. London: Academic Press, 1975, p. 309-323.

MELO, L. R. R. Utilização de carne de caprinos de descarte na fabricação de um embutido cozido, tipo apresuntado. Fortaleza, 1998. 58 p. Dissertação - (Mestrado em Tecnologia de Alimentos) - Universidade Federal do Ceará.

NATIONAL RESEARCH COUNCIL - NRC. Nutrient requeriment of sheep. 6 ed. Washington, D.C.: National Academy of Science, 1985. $99 \mathrm{p}$.

ORDÓNEZZ, J. A. et al. Changes in the components of dry-fermented sausages during ripening. Critical Reviews in Food Science and Nutrition, v. 39, n. 4, p. 329-367, 1999.

ROÇA, R. O. et al. Avaliação comparativa da carne de cordeiro e ovelha e de seus produtos derivados. In: Congresso Brasileiro de Medicina Veterinária, 25, 1997, Gramado. Anais... Gramado, Rio Grande do Sul, 1997. $301 \mathrm{p}$.

RODEL, W.; STIEBING, A.; KROCKEL, L. Ripening parameters for traditional dry sausages with a mould covering. Fleischwirtschaft, v. 73, n. 8, p. 848-853 1993.

RUSSEL, A. J. F.; DONEY, J. M.; GUNN, R. G. Subjective assessment of body fat in live sheep. Journal Agricultural Science, v. 72, p. 451-454, 1969.

RUST, R. E. Productos Embutidos. In: PRICE, J. F.; SCHWEIGERT, B. S. Ciência de La Carne y de Productos Carnicos. 2 ed. Zaragoza: Acríbia, 1994. p. 415-440.

SAS. Sas Institute Inc. Cary, NC, 1997.

SILVEIRA, E. T. F.; ANDRADE, J. Aspectos tecnológicos de processamento e qualidade de embutidos fermentados. Campinas: FEA/UNICAMP, 1991.

TERRA, N. N.; BRUM, M. A. R. Carne e seus derivados- técnicas de controle de qualidade. São Paulo: Nobel, 1988. 121 p.

ZAPATA, J. F. F. Tecnologia e comercialização da carne ovina. In: Semana da Caprinocultura e da Ovinocultura Tropical Brasileira, 1994, Sobral. Anais... Brasília: EMBRAPA-SPI, 1994. p. 115-128. 